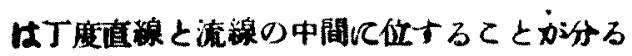

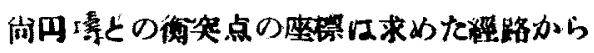
$x^{2}+y^{2}=1$ 方保件て Newton の内掩式等に依 り求みること加奻來る

\title{
8 結語
}

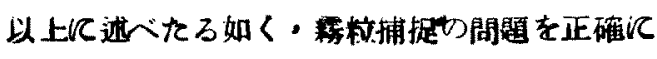

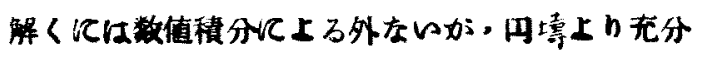

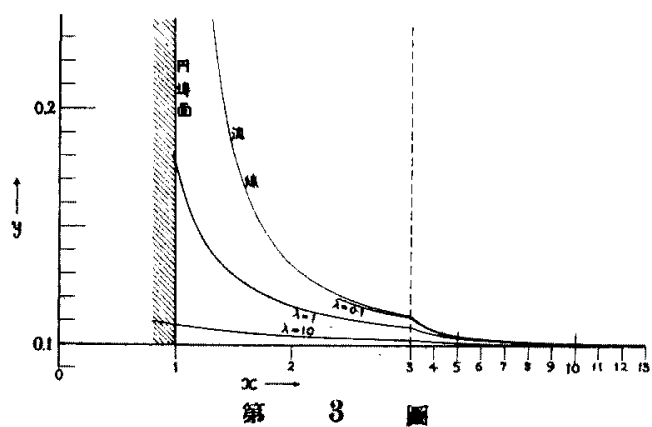

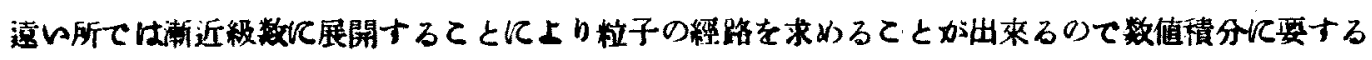

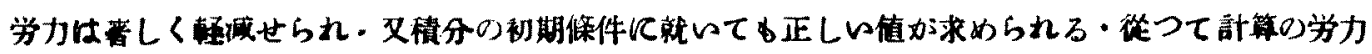

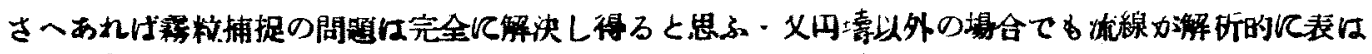
し得るならげ同榜の方法て解くことが可能てある

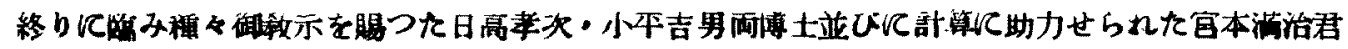
に対し深謝の意を表なる・向本研究は文部省科学研究費の補助を受けた・

\section{遠距離風信器 0 一案”}

\section{武田京 - -}

\section{1 緒言}

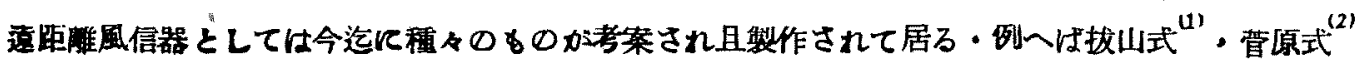

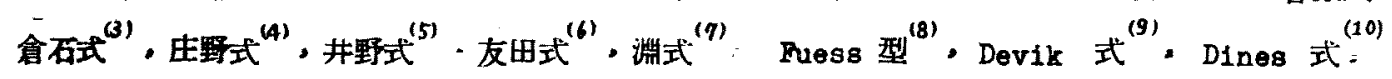

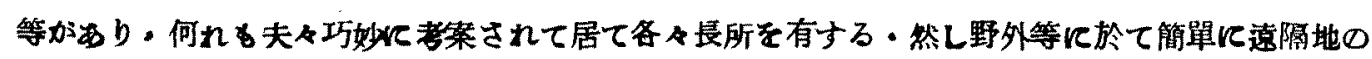

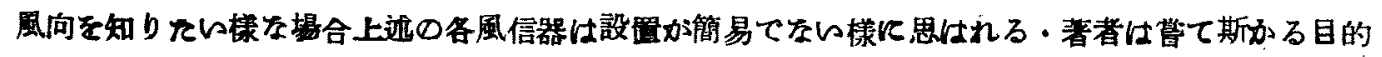

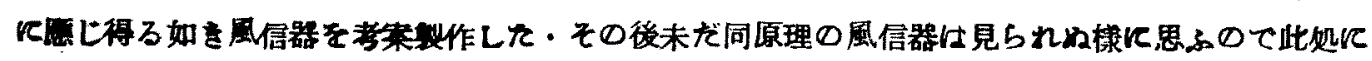
発表させて頂くことにした

\section{2 造}

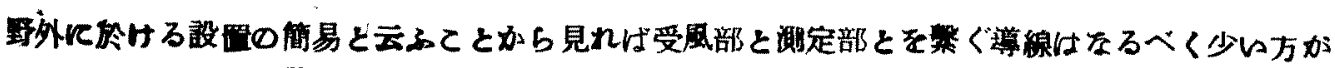

- R. Takedas T Distant Reading Wind Vane.

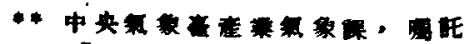

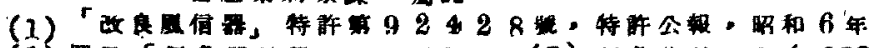

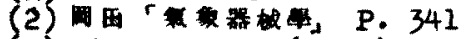

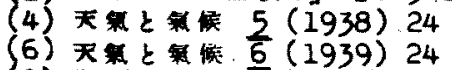
(3) 集的 16 (1938) 457
(8) 2. Inst:. $\frac{9}{9}(188 y) 90$
(10) Met. Mag. $72(1937)^{3}$
（5）天策侯 $5(1938) 268$
(7) Geophs. Mag. $\frac{5}{5}$ (1932) 33
(9) 2. Instr. 48 (1928) 218 


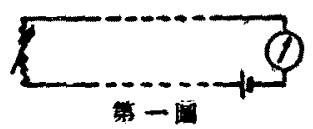

第一间

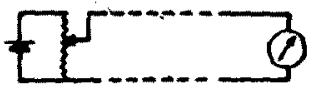

第二西

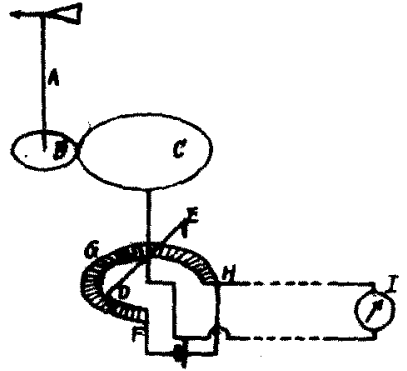

箱三

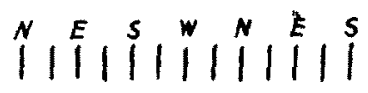

第四四

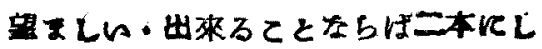

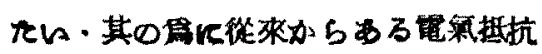

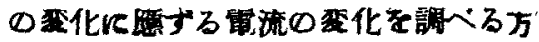
式を探用して・然し第一四の如等方式

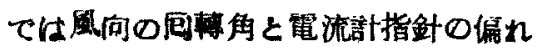

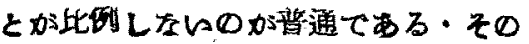

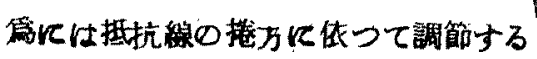

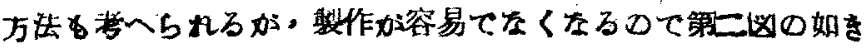

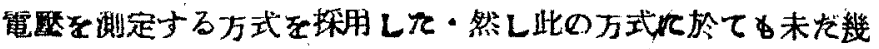

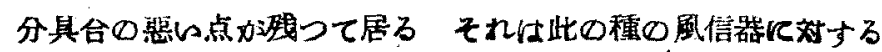
共通の缺点とも云い得るで西 5.5 か抵抗の最大と最小との間に

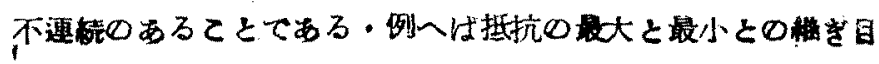

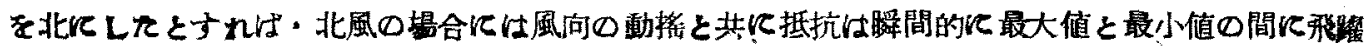

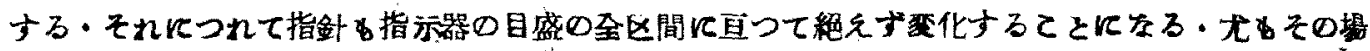

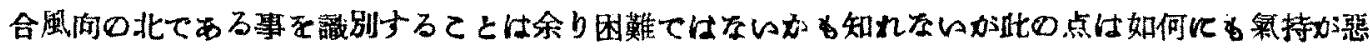

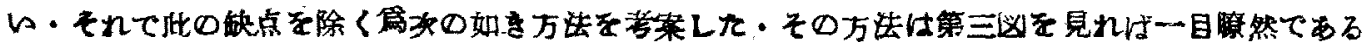

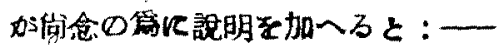

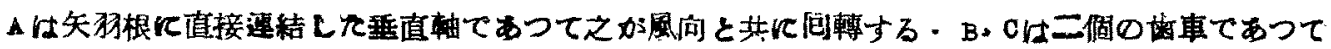

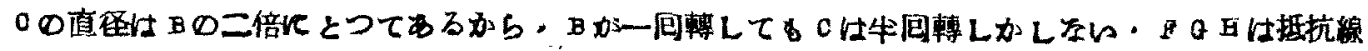

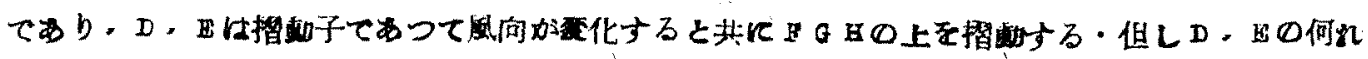

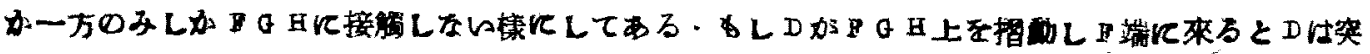

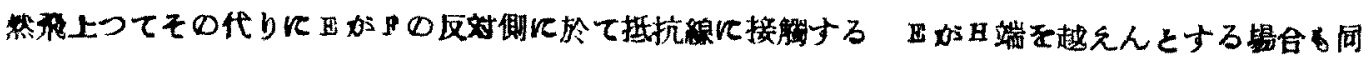
桡てある

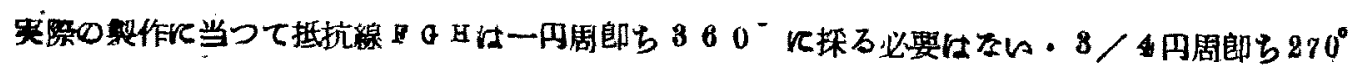

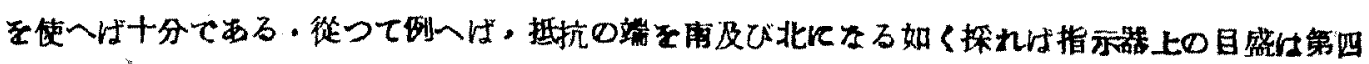

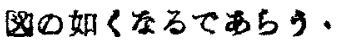

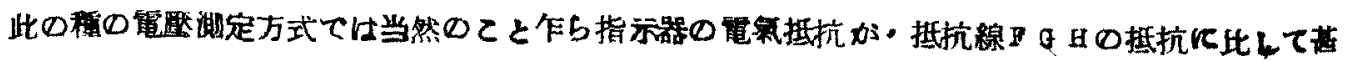

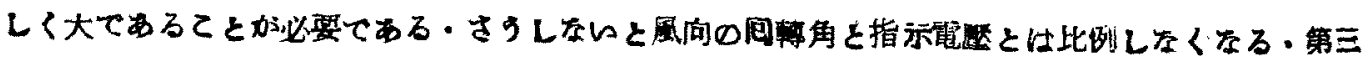

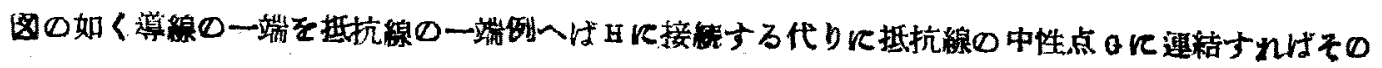

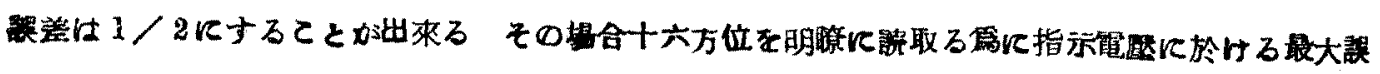

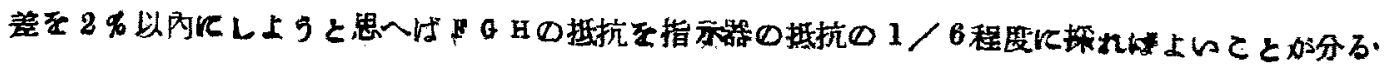

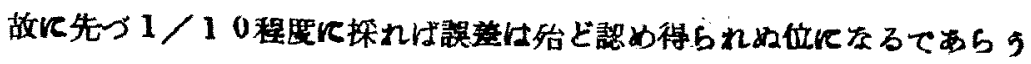

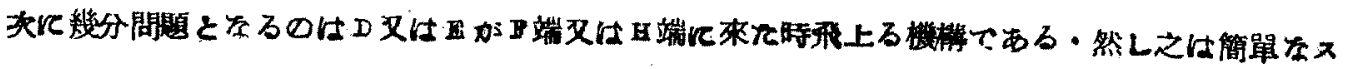




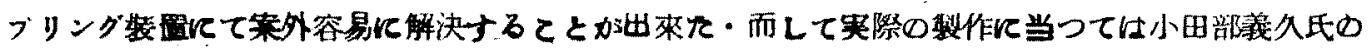

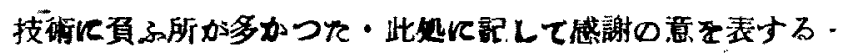

\section{空中電氣の变化と氣象狀況についで (其の一大氣電氣傳導度の変化)

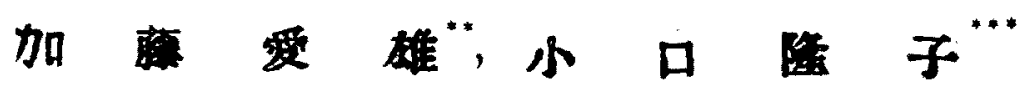

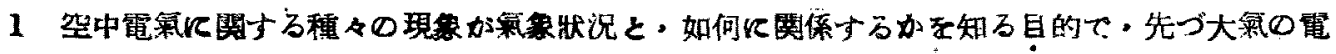

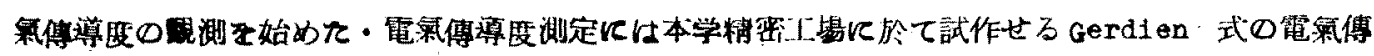

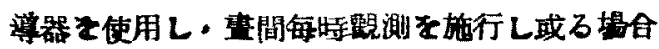

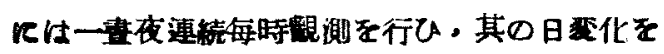
明らかルした・現在をでに得てる若干の成果 こつに啹告する・

2 政測結果

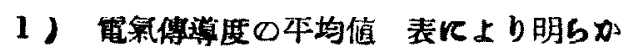

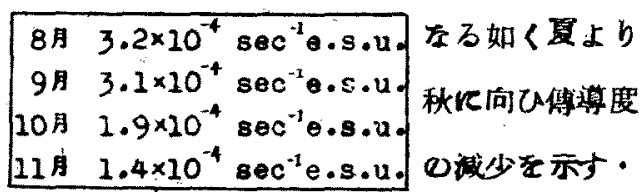

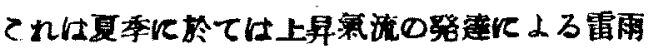

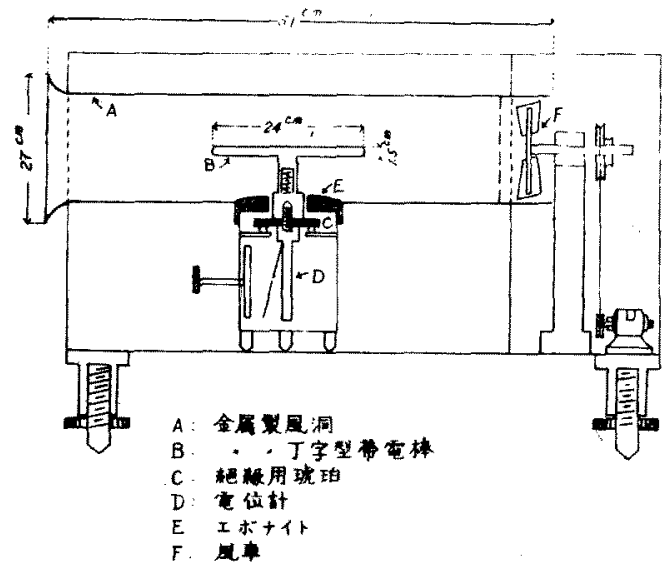

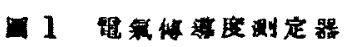

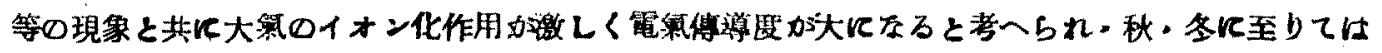

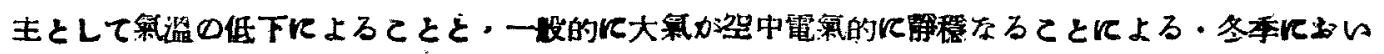

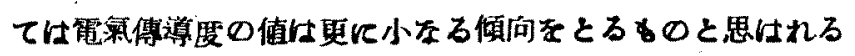

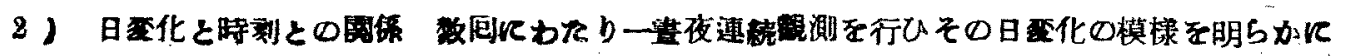

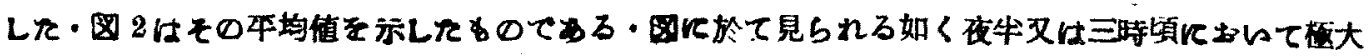

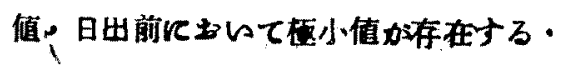

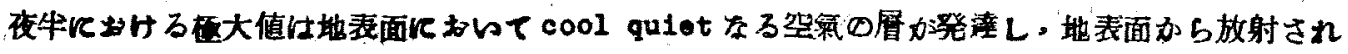

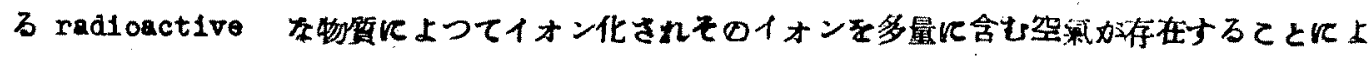

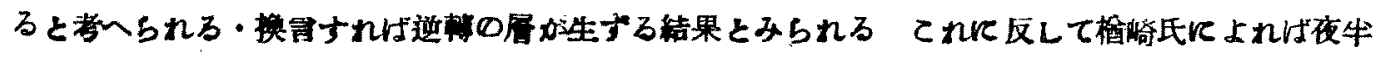

- Y. Kato and T. Ogut1: The Changes of the Eleotrical Conductivity of Atmosphere lccompanied by the Changes of Weather Condition. 